\title{
Wolf Lepenies: Homo Europaeus Intellectualis revisitado ${ }^{1}$
}

\author{
Wolf Lepenies: Homo Europaeus Intellectualis revisited \\ Wolf Lepenies: Homo Europaeus Intellectualis revisado
}

\author{
Marek Kwiek ${ }^{2}$ \\ Tradução: Rosangela Molento Ferreira ${ }^{3}$ \\ Revisão técnica: Luiz Carlos Barreira ${ }^{4}$
}

\section{Resumo}

O autor revisita as narrativas de Wolf Lepenies sobre os papeis desempenhados pelos intelectuais na história da Europa contemporânea, situando-as no interior de uma oposição que estruturou o pensamento do sociólogo nos últimos vinte e cinco anos do século $\mathrm{XX}$, pelo menos: a da melancolia e utopia. Tal par não apenas no permite ver o passado dos intelectuais no Oeste e no Leste europeus após os acontecimentos de 1989 (a queda do Muro de Berlim e a extinção do Estado soviético) de uma perspectiva distinta (daquela que valoriza o engajamento político do intelectual, por exemplo), mas também nos permite examinar cuidadosamente o lugar do intelectual no mundo de hoje, após a queda das duas grandes utopias da modernidade: a utopia comunista do fins e a utopia capitalista dos meios.

Palavras-chave: Intelectuais; Wolf Lepenies; Melancolia e Utopia.

\footnotetext{
${ }^{1}$ Publicado originariamente em Philosophie an der Schwelle des 21. Jahrhunderts, E. Czerwinska-Schupp (Hrsg.), Frankfurt a/Main e New York: Peter Lang, 2003, p. 329-349.

2 Diretor do Centro de Estudos de Políticas Públicas e Presidente da Cátedra Unesco em Pesquisa Institucional e Política de Educação Superior. Universidade de Poznan, Polônia. E-mail kwiekm@amu.edu.pl

${ }^{3}$ Doutoranda do Programa de Pós-graduação Stricto Sensu em Educação da Universidade Católica de Santos. Professora da Faculdade de Tecnologia da Baixada Santista do Centro Estadual de Educação Tecnológica Paula Souza. E-mail romolento@ hotmail.com

${ }^{4}$ Doutor em Educação pela Universidade Estadual de Campinas, com estágio de pós-doutorado realizado na Universidade de Lisboa. Professor do Programa de Pós-graduação em Educação da Universidade Católica de Santos. E-mail luiz.barreira@unisantos.br
} 


\begin{abstract}
The author revisits Wolf Lepenies' narratives on the roles played by intellectuals in the history of contemporary Europe, placing them within an opposition that has structured the sociologist's thinking in the last quarter of the twentieth century or so: that of melancholy and utopia. Such a pair not only allows us to see the past of intellectuals in Western and Eastern Europe after the events of 1989 (the downfall of the Berlin Wall and the extinction of the Soviet state) from a different perspective (from the one that values the political engagement of the intellectual, for instance), but also allows us to look carefully at the intellectual's place in today's world, after the downfall of the two great utopias of modernity: the communist utopia of ends and the capitalist utopia of means.
\end{abstract}

Keywords: Intellectuals; Wolf Lepenies; Melancholy and Utopia.

\title{
Resumen
}

El autor retoma las narraciones de Wolf Lepenies sobre los papeles desempeñados por los intelectuales en la historia de la Europa contemporánea, ubicándolas en el interior de la oposición que ha estructurado el pensamiento del sociólogo en el último cuarto del siglo XX, por lo menos: el de la melancolía y la utopía. Tal par no sólo nos permite ver el pasado de los intelectuales en el Oeste y en el Leste europeos después de los acontecimientos de 1989 (la caída del Muro de Berlín y la extinción del Estado soviético) desde una perspectiva distinta (de la que valora el compromiso político del intelectual, por ejemplo), pero también nos permite examinar cuidadosamente el lugar del intelectual en el mundo de hoy, tras la caída de las dos grandes utopías de la modernidad: la utopía comunista de los fines y la utopía capitalista de los medios.

Palabras clave: Intelectuales; Wolf Lepenies; Melancolía y Utopía. 
As questões sobre o lugar e o papel do intelectual na sociedade, suas tarefas e obrigações, o status que ele atribui a si mesmo e que a sociedade atribui a ele tornaram-se, recentemente, parte significativa do discurso atual nas ciências humanas. Existem diferentes motivos em diferentes países para isso, mas, nos países de língua inglesa, na Alemanha ou, especialmente, na França, questões sobre os intelectuais foram importantes pontos de referência em numerosas discussões do final do século XX. O pensamento de Lepenies mostra, de forma convincente, que o discurso francês dominante sobre o assunto requer um complemento significativo hoje, pois retrata apenas uma parte de um todo maior que não se limita à França, e as questões francesas sobre os intelectuais (desde o caso Dreyfus, na virada do século XX, a Sartre e le silence des intellectuels ${ }^{5}$, na década de oitenta do século passado) não esgotam o rol de questões que podem e devem ser feitas hoje, nem restringem nossas considerações sobre intelectuais à aventura de escritores e filósofos franceses de terem sido seduzidos pelo pensamento marxista (ou stalinista), que começou com a Revolução de Outubro de 1917 e continuou até meados dos anos setenta em decorrência, tão somente, da decepção desses escritores e filósofos com tal pensamento e do distanciamento gradual em relação a ele após a guerra de independência da Argélia e os eventos de 1956 (pois, de fato, é possível ver a história dos intelectuais franceses do século XX também desta perspectiva); além disso, essas questões, que remontam principalmente à história - e especialmente àquela da França do século XX - basicamente não são consideradas em relação ao presente e ao futuro (ver JUDT, 1992; JENNINGS, 1993).

E esta talvez seja a diferença mais importante, em um discurso devotado ao intelectual, entre a Alemanha (e a América), por um lado, e a França por outro lado. A peculiaridade cultural destes países pode ser bastante considerável: parece que a América, com exceção de Dewey nos anos de 1930, não teve grandes intelectuais públicos, nem grandes discussões sobre seu engajamento social e a responsabilidade associada a eles que derivava diretamente da história francesa (KWIEK, 2003a; KWIEK, 1998; RORTY, 1998). O intelectual socialmente engajado como Sartre, que não apenas fala - mas que também é ouvido - não encontra um lugar confortável na tradição alemã (e lembremo-nos aqui de Lepenies em Entre a Literatura e a Ciência: o Surgimento da Sociologia: "Na Alemanha, a escrita e a leitura são atos tradicionalmente solitários, e uma literatura conscientemente preocupada com o que afeta a sociedade, e firmemente ancorada nela, sempre foi considerada como superficial e não alemã" [LEPENIES, 1988: 204]). Talvez seja esse o motivo dos pensadores melancólicos franceses parecerem ter um discurso retrógrado, enquanto os teóricos americanos e alemães, correndo o risco, por um momento, de uma simples generalização excessiva, olham adiante, passado e presente em direção ao futuro. A América é tradicionalmente um "país voltado para o futuro" com seus próprios mitos e sonhos da terra prometida; "o sonho americano" não é um dos tratados intelectuais, é uma parcela do mundo social que foi submetida a um duro teste após a guerra do Vietnam e, mais recentemente, pela tragédia de 11 de setembro (KWIEK, 2003). Nem Edward Said, Paul Bové, Noam Chomsky ou Richard Rorty - para citar alguns entre os que escrevem mais extensamente nos EUA sobre o intelectual no final do século XX - retornam aos dilemas morais de eventos passados. Ao invés disso eles fazem uma pergunta diferente: o que deve ser feito hoje?

De modo semelhante, os pensadores alemães parecem ter olhado com espanto, pelo menos até ter se tornado um debate internacional, para as intensas discussões francesas sobre o engajamento político de Martin Heidegger em 1933, que aconteceu no final da década de

\footnotetext{
${ }^{5}$ o silêncio dos intelectuais (N.T.)
} 
oitenta - considerando o caso como encerrado, pelo menos na Alemanha (KWIEK, 1999). A especificidade francesa, por outro lado, parece consistir em fazer perguntas sobre o presente por meio de desvios conduzidos com a ajuda de perguntas feitas sobre o passado; daí os recentes retornos a Dreyfus, Benda, Sartre, muitas vezes só para ajustar considerações e travar as guerras filosóficas atuais (ver Pourquoi, 1991). Então, enquanto se pensa sobre a questão do intelectual hoje, é importante ter em mente o fato de que o nosso discurso sobre esta figura permanece à sombra de um discurso francês de lastro histórico sobre o assunto, negligenciando em grande parte os discursos alemães e americanos (não tão dramáticos, heroicos, espetaculares!) que acontecem simultaneamente.

\section{2.}

O tema do "intelectual" desempenha um papel fundamental nos escritos de Wolf Lepenies; parece que seu trabalho, de Melancholie und Gesellschaft ${ }^{6}$ a Die Drei Kulturen ${ }^{7}$ e a Aufstieg und Fall der Intellektuellen in Europa ${ }^{8}$, assim como sua aula inaugural no Collège de France, proferida em 1992 (La fin de l'utopie et le retour de la mélancolie. Regards sur les intellectuels d'un vieux continent ${ }^{9}$ ), e numerosos artigos publicados nos anos recentes, pode ser lido desde a perspectiva do intelectual moderno. Neste texto pretendo apresentar as narrativas de Lepenies sobre o intelectual e localizá-las no interior da oposição que estruturou o seu pensamento pelo menos nos últimos vinte e cinco anos: a da melancolia e utopia. O elo melancolia-utopia-intelectual é um elo de três elementos inseparáveis em seu pensamento. Nenhum deles existe independentemente em seus trabalhos: "Melancolia e utopia - é entre estes dois polos que reside a grandeza e a miséria dos intelectuais europeus" (LEPENIES, 1992, p. 20). Este é um dos temas mais estimulantes, mais constante - e frutífero - em seu trabalho; é o que fornece insights em sua narrativa sobre violência e revolução, terror, totalitarismo, como também o mundo pós-Guerra-Fria de hoje. O par oferece instrumentos a Lepenies para analisar a situação dos intelectuais no Oeste e no Leste da Europa depois de 1989. Verifica-se hoje que o par melancolia/utopia não apenas permite ver o passado dos intelectuais de uma perspectiva diferente, mas também nos permite ter um olhar cuidadoso sobre seu lugar no mundo hoje, depois - em simultâneo, como ele destaca - da queda das duas grandes utopias da modernidade: a utopia comunista dos fins e a utopia capitalista dos meios. Lepenies nos mostra em seus trabalhos que o par melancolia/utopia é útil na discussão do papel dos intelectuais: a melancolia específica dos intelectuais que deriva das inadequações do mundo em que vivem e o qual são incapazes de mudar, e suas utopias que derivam da inibição de atitude e transferência dos sonhos não realizados neste mundo para um mundo melhor. A utopia que Lepenies escreve deriva da melancolia dos intelectuais e, ao mesmo tempo, é um modo de curá-los disso.

A utopia, na narrativa de Lepenies, é um produto das representações de uma classe social que perdeu sua significância pública e política, ou uma classe que aspira ter tal significância sabendo que isto (aqui e agora) é impossível. A utopia é uma sombra da melancolia, são gêmeas. Ela nasce sempre que uma atividade social é bloqueada e reduzida à passividade impotente. Quando as possibilidades de ação diminuem, a reflexão aumenta, mas o intelectual melancólico sofre porque ele não é capaz de agir - só consegue pensar.

\footnotetext{
${ }^{6}$ Melancolia e Sociedade (N.T.)

${ }^{7}$ As Três Culturas (N.T.)

${ }^{8}$ Ascensão e Declínio dos Intelectuais na Europa (N.T.)

${ }^{9}$ O Fim da Utopia e o Retorno da Melancolia. Visões sobre os Intelectuais de um Velho Continente (N.T.)
} 
"Weltschmertz $z^{10}$, melancolia e hipocondria resultaram da hipertrofia forçada do campo da reflexão, da perda imposta de uma habilidade para exercer o verdadeiro poder, e da consequente pressão para justificar essa situação" (LEPENIES, 1992, p. 61). O intelectual rejeita o mundo no qual ele é incapaz de agir, retira-se da sociedade para dentro de si, sofre com o seu destino e o do mundo, tentando expressar esse destino em comum (como Paul Valéry - que tenta changer ses doulers en oeuvre ${ }^{11}$ ) e, finalmente, sofre com o que restou que é apenas a reflexão. O homo europaeus intellectualis, como Lepenies o chamou em sua palestra no Collège de France, não é um cientista social tentando conquistar o mundo para compreendê-lo e fornecer prognósticos, ele também não é o cientista ou o técnico. Ele é o melancólico, o intelectual que é chroniquement insatisfait ${ }^{12}$, que pensa e duvida e, finalmente, se retira deste mundo em busca de um melhor, experimentando sua incapacidade.

O que Lepenies mostra em sua Melancolia e Sociedade é que o pensamento utópico deriva da insatisfação com o status quo social do intelectual. Esta falta de satisfação não leva e nem é sua intenção - a uma ação. As utopias, como são apresentadas por Lepenies, não são manifestos revolucionários que mostram o ponto de partida (a atual situação miserável), o ponto de chegada (a futura sociedade radiante e feliz) e os supostos caminhos que deveriam levar de um ponto ao outro. O primeiro caso de utopia já foi apresentado por Robert Burton, em Anatomia da Melancolia, de 1621, cuja ideia Lepenies expressa de maneira clara: Burton "planejou sua utopia da Inglaterra pois, como um intelectual pobre, ele nunca poderia esperar que suas ideias fossem colocadas em prática", e os utópicos, em geral, "não pensariam e planejariam desta maneira se eles pudessem agir" (LEPENIES, 1992b, p. 146). O intelectualmelancólico-utópico, enquanto cria a utopia, é mais um terapeuta (com respeito a si mesmo e à sua classe) do que um revolucionário. A utopia nasceu da melancolia e é um meio de combatêla. Espera-se que ela cure o seu criador ao invés do mundo - curar de sua falta crônica de satisfação, da não realização de suas aspirações públicas e políticas, e da privação dos sonhos de participação no verdadeiro poder político. A utopia não requer ação - "precisamente porque está documentado na literatura, o pensamento utópico é um sinal de inibição da ação" (p. 146). A ação é impossível e o intelectual é um homem de ação infeliz e insatisfeito.

A utopia, como um produto do intelectual-melancólico, é organizada pela noção de ordem: se não há melancolia em um mundo melhor, então também não há lugar para o aborrecimento: a utopia "divide o tempo, até o último ponto, uma vez que pareceria mais fácil criar uma vida nova para preservar a utopia (Campanella). Não existe tempo livre na utopia, porque não há espaços vazios disponíveis a serem excluídos do plano. O trabalho, assim como o tempo de lazer, é cheio de regras" (LEPENIES, 1992b, pp. 91-92). Para se livrar da melancolia, do tédio, do aborrecimento, o plano utópico deve ser abrangente e a ordem e o tédio devem ser mutuamente exclusivos. Mas o ponto crucial é que a noção de ordem, plano e espaço finito de possibilidades colide com a reflexão e, finalmente, a torna impossível. A utopia do intelectual-melancólico nasceu da reflexão sobre as inadequações deste mundo, mas conduz a uma visão de um mundo melhor no qual, para citar Lepenies novamente, "não há mais nenhum espaço para a reflexão, porque tudo está 'em ordem”' (p. 147). Quando não há mais lugar para a reflexão, podemos falar em paraíso (o que se pode querer mudar em um mundo absolutamente perfeito?); quando não há mais lugar para a reflexão, no entanto, podemos falar também no inferno do totalitarismo (no qual a mudança não pode ser sequer pensada). Na utopia, a história cessa inesperadamente, fica imóvel e encontra seu fim. O

\footnotetext{
${ }^{10}$ Não há um termo correspondente em português para Weltschmertz. Expressa, de acordo com o uso que o autor do texto dele faz, um sentimento profundo de tristeza diante da incapacidade de o mundo "real" atender nossas expectativas, realizar nossos desejos. Nesse sentido, não poder "realizar" o que se deseja produz sensações de impotência e angústia (N.T.)

${ }_{11}$ transformar sua dor em ação (N.T.)

12 cronicamente insatisfeito (N.T.)
} 
tempo para assim que é medido pelas mudanças. No novo mundo da utopia - nascido das reclamações sobre as inadequações e imperfeições do mundo atual - nada mais pode ser mudado ou, como afirma Lepenies, o espaço criado é "definitivo" (p. 148). A utopia tem conseguido dissipar o tédio, livrar-se da melancolia, fazer a hipocondria ir embora - com a parada do tempo e da história.

Lembremo-nos que os temas do "fim da história" e do "fim do pensamento" têm estado presentes na filosofia pelo menos desde a Fenomenologia do Espírito, de Hegel: juntamente com um "julgamento autoconsciente" de Hegel e uma "ação autoconsciente" de Napoleão, a história tornou-se completa na batalha de Jena. Hegel não pode prescindir de Napoleão e vice-versa - é em Napoleão que Hegel encontra a sua certeza de ser um sábio (e não um mero filósofo) que possui o Conhecimento Absoluto, por isso é devido a ele que a realidade que ele está descrevendo na Fenomenologia é definitiva. A questão sobre o homem depois do fim da história - como também sobre o intelectual depois do fim dela - é a chave para Alexandre Kojève, um grande comentarista de Hegel na França, que exerceu uma influência peculiar e duradoura sobre toda a geração dos pensadores e escritores franceses no período de, aproximadamente, 1930-1960. Kojève perguntaria o que o homem "pós-histórico" faria se a ação que nega a realidade não é mais necessária, sendo irracional como é o mundo pós-histórico, o mundo da verdade incorporada? E quanto à felicidade e satisfação humanas? O homem não está condenado a sofrer do tédio pós-histórico? O que se espera que ele faça com sua "negatividade sem emprego" - a négativité sans emploi ${ }^{13}$ de Georges Bataille, um outro leitor de Hegel - e quem será o intelectual, portador dessa negatividade sem emprego depois do fim da história (KWIEK, 1997; KWIEK, 1999)? O que acontece com a negatividade de alguém que, de repente, não tem nada mais a fazer ou, para fazer uma pergunta mais fundamental, seguindo o caminho indicado por Lepenies sobre a impossibilidade de reflexão na utopia no momento em que a história chega a um fim: quando tudo for finalmente conhecido, e quando a sociedade finalmente for perfeita, o que o intelectual será capaz de fazer e de conhecer? (O que acontecerá com toda a tradição que remonta à antiga filosofia segundo a qual a essência do ser humano está no conhecimento?) O que ele será capaz de escrever se a escrita está associada à história em curso - mutável, interminável, imprevisível - que está prestes a acabar? A resposta de Lepenies é inequívoca neste ponto: com o banimento da melancolia na sociedade do futuro, não haverá mais lugar disponível para a reflexão ou para o intelectual. As perguntas de Hegel (eu não seria Deus se possuísse o Conhecimento Absoluto e tivesse me tornado o primeiro Sábio?), que têm assombrado o pensamento francês do século XX, de Kojève, Bataille, Blanchot a Denis Hollier, encontram em Wolf Lepenies suas respostas de forma explícita. Poder-se-ia dizer o seguinte: a utopia, como um produto do intelectual-melancólico, é um mundo do qual ele não faz mais parte. $\mathrm{O}$ mundo perfeito não precisa de pessoas cuja tarefa consiste em procurar suas imperfeições (pois "certamente é verdade que os intelectuais podem cumprir melhor sua missão como heréticos e críticos, como inconformistas e oposicionistas", completa Lepenies [1991, p. 914]). Nenhum dos papéis sociais enumerados por ele acima é necessário no mundo da utopia; além disso, cada um deles pode facilmente se tornar perigoso em tal mundo. "Dans l'utopie, la mélancolie est strictement interdite"14... A interdição existente nas utopias literárias é, na verdade, transformada em sociedades que afirmam ser a realização de utopias no "dever da felicidade imposta" - com a ajuda da violência, se for necessário. Felicidade, regozijo, jovialidade são características de utopias realizadas até agora, como a fé, na criação do novo homem. O novo homem na nova sociedade tem de ser feliz. Ele não é autorizado a

\footnotetext{
${ }^{13}$ negatividade sem emprego, porque se fez desnecessária (N.T.)

14 "Na utopia a melancolia é estritamente proibida" (N.T.)
} 
expressar em público sua infelicidade, sua melancolia ou falta de satisfação. A ele não é permitido discutir, pensar ou escrever.

$\mathrm{Na}$ oposição sugerida entre die klagende Klasse ${ }^{15}$ e die Menschen guten Gewissens ${ }^{16}$ (ou como ele sempre diz l'espèce qui se plainte ${ }^{17}$ e les hommes de bonne conscience ${ }^{18}$ [LEPENIES, 1992a, p. 17; 1992, p. 18]), Lepenies vai além da tradicional oposição das "duas culturas" apresentada por C. P. Snow. Ele mostra que os dois polos: melancolia e utopia não afetam os cientistas sociais, por exemplo, os sociólogos. A sociologia é precisamente a "terceira cultura" nascida da impossibilidade de se tornar uma versão "social" das ciências naturais, por um lado, e a impossibilidade de escolher a literatura na descrição do mundo social, por outro. A divisão que Lepenies tem em mente não vem da cultura dos humanistas e homens de letras, por um lado, e dos cientistas naturais, por outro. O livro intitulado Die drei Kulturen ${ }^{19}$ (e traduzido para o inglês como Between Literature and Science: the Rise of Sociology) é dedicado à disputa entre os homens de letras e os cientistas sociais, para fornecer a orientação-chave para a civilização moderna, com vistas à constituição de um guia para uma vida adequada à sociedade industrial, bem como ao próprio status do conhecimento sobre a sociedade industrial que vem ocorrendo a partir de meados do século XIX. O dilema não é mais a escolha entre as ciências naturais e as humanidades, a antiga disputa entre Naturwissenschaften $^{20}$ e Geisteswissenchaften ${ }^{21}$; o ponto de análise de Lepenies é a controvérsia entre intelligentsia literária e as representações das ciências sociais que, por sua vez, nos remete à controvérsia entre a cultura da razão e a cultura dos sentimentos, o Iluminismo e o anti-Iluminismo (ver também LEPENIES, 1999) (ou, num plano diferente, os perigos de um cientificismo ou literaturização da sociologia). A tensão que permeia seus trabalhos e que surgiu entre os humanistas queixosos e os cientistas sociais autocomplacentes não aparece na oposição das "duas culturas". A ciência social está localizada além da alternativa que os intelectuais, por exemplo, artistas e escritores, têm diante de si: melancolia ou utopia, estando ao mesmo tempo "par delà la mélancolie et en-deça de l'utopie 22 " (LEPENIES, 1992, p. 20). A oposição tradicional das "duas culturas" requer um significado complementar na forma de uma "terceira cultura", a cultura das ciências sociais ou sociologia, em particular. Caso contrário, a história dos intelectuais do século XX - como também os primeiros "intellectuels avant la lettre ${ }^{23 "}$ - será incompreensível.

O intelectual não age mesmo que queira. Ele quer, mas não pode. Privado da real influência sobre o exercício do poder, ele se retira deste mundo para um mundo melhor de reflexão. Desde o início do século XIX, Lepenies afirma, em "O futuro dos intelectuais" (LEPENIES, 1994), que os sonhos do Iluminismo com a interpretação e mudança do mundo começaram a desaparecer quando Napoleão mudou o mapa da Europa. Eram necessários engenheiros para efetuar os progressos técnicos e burocratas para gerenciar as massas; já não havia mais lugar para uma elite intelectual improdutiva, acreditando que os princípios poderiam governar a sociedade. Como comenta o autor, neste período, "o resultado foi a resignação e a revolta por parte dos intelectuais. Eles se consolavam com a ideia de que seu reino não era deste mundo" (LEPENIES, 1994, p. 116). Na narrativa de Lepenies, basicamente não há, na França, um lugar significativo atribuído ao "caso Dreyfus" e o nascimento do termo "intelectual” no final do século XIX; ao contrário de Bernard-Henri

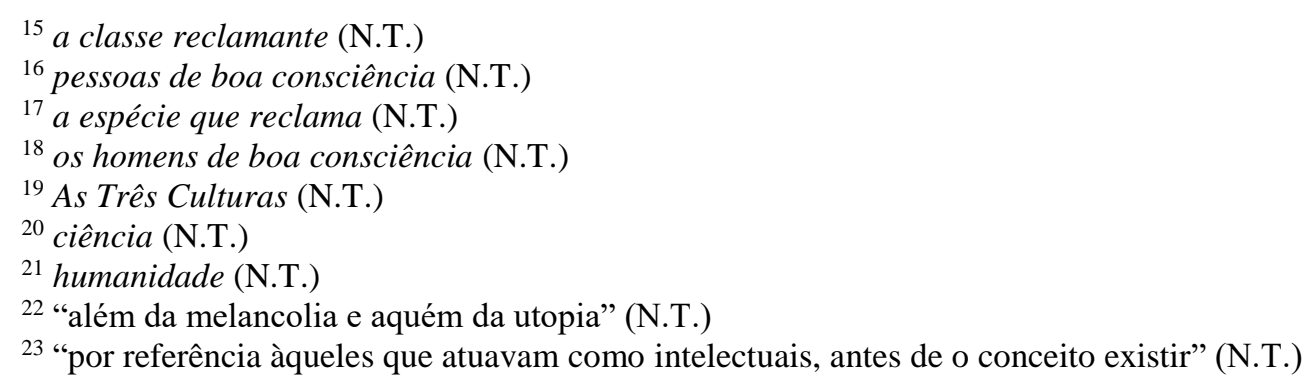


Lévy, de Les aventures de la liberté24, ele toma esse momento específico como menos importante que outros dois eventos: o artigo de Diderot sobre o "filósofo", escrito para sua Enciclopédia, que atribui modestas tarefas do Iluminismo ao filósofo, e a Revolução Russa de Outubro de 1917. O ano 1917, em seu registro, completava 1789 - "os intelectuais tinham, por fim, mudado o mundo também". O comunismo e, depois, o fascismo prometeriam a realização de um antigo sonho no qual as ideias podem tornar-se parte da realidade. Lepenies explica a força atrativa do comunismo para os intelectuais por meio de sua relação com a ação - depois do colapso do fascismo "permaneceu apenas uma ideologia da ação, e foi em direção a esta ideologia que o homem limitado de ação, o intelectual, direcionou-se, concordando com isso ou não" (117). Se o desejo era complementar a narrativa de Lepenies sobre o "homem limitado de ação" com alguns detalhes do contexto francês, então seria importante ressaltar que o fascínio exercido pelo comunismo sobre os intelectuais franceses foi fortemente abalado pela primeira vez em 1954 com o advento dos eventos na Argélia. Depois do manifesto dos "121 intelectuais" em conexão com a guerra argeliana, apareceu um novo tipo de ideologia direcionando os intelectuais para o Terceiro Mundo (ver a carreira de Frantz Fanon). Para citar Lévy: "nossos intelectuais ainda não haviam sido curados. Certamente eles não se importavam mais com a União Soviética e nem acreditavam em Stalin. Mas sua fé na revolução autêntica e genuína, que colocaria um fim aos males do Ocidente, permaneceu intacta" (LÉVY, 1995, p. 43).

\section{3.}

No entanto, as propostas e intuições de Lepenies vão em outra direção. Ele não está preocupado com o renascimento de l'engagement ${ }^{25}$ como apresentado por Sartre em "O que é literatura?", nem está preocupado com as tarefas apresentadas por Michel Foucault ao intelectual francês quando tentou ir além da concepção sartriana do intelectual como um escritor em sua oposição inacabada e não elaborada - intellectuel universel/intellectuel spécifique ${ }^{26}$ (STOEKL, 1992; READER, 1987). A chave aqui é o ano de 1989; Lepenies em várias ocasiões afirma que "1989 não aconteceu apenas no Oriente. Aconteceu no Ocidente também" (LEPENIES, 1995, p. 3). Devemos focar nas consequências que ele trouxe para a constelação de questões sobre melancolia-utopia-intelectuais. Primeiramente, algo aconteceu com a melancolia, algo aconteceu com a utopia e algo aconteceu com os intelectuais, tanto na Europa ocidental quanto na oriental. O sonho de um mundo livre, de uma democracia parlamentar, tornou-se realidade na Europa Central e Oriental (como Lepenies escreveu em suas palestras italianas de 1992, "Die Utopie von gestern schien zur Wirklichkeit von heute geworden"27 [LEPENIES, 1992a, p. 47]). A melancolia causada pela falta de influência pública e política cedeu lugar à euforia - e então apareceu o fenômeno dos "melancólicos ativos", intelectuais que, de uma maneira inesperada aos outros e a eles mesmos, depois de anos de oposição, ganharam poder. Estava perdido o equilíbrio tradicional na constelação dos três elementos em questão: é possível ser intelectual e governar ao mesmo tempo? É possível ser, simultaneamente, um homem de ação e um melancólico? É possível ser um utópico e governar a sociedade? O que deve ser feito - e pensado - quando o então conceito tradicional de intelectual não mais se refere aos intelectuais no poder? Em que eles se tornam - exintelectuais, ex-melancólicos, ex-utópicos? Como é que os "intelectuais culturais" da Europa Central enfrentam a "cultura de especialistas" da Europa Ocidental (com relação à educação, ver KWIEK, 2003)?

\footnotetext{
${ }^{24}$ As Aventuras da Liberdade (N.T.)

${ }^{25}$ o compromisso (N.T.)

26 "intelectual universal/intelectual específico" (N.T.)

27 "A utopia de ontem parecia se tornar a realidade de hoje" (N.T.)
} 
Os intelectuais na Europa Central chegaram ao poder por mecanismos que são totalmente desconhecidos no Ocidente como experiência própria; voltando a Lepenies: "Sua luta por direitos humanos, o ideal clássico do intelectual europeu moderno, dotou os intelectuais do Leste e do Centro europeu com certos direitos inalienáveis e um grau de credibilidade política que nenhum intelectual do Ocidente poderia adquirir. Eles também demonstram (...) um novo entusiasmo emocional que tem estado ausente nas discussões dos intelectuais do Ocidente por um longo tempo". Nem sua experiência política e econômica levou-os ao poder - eles o conseguiram devido à sua "sinceridade artística" e sua "probidade moral" (LEPENIES, 1991, p. 915-916). O fascínio de Lepenies com os intelectuais por detrás da antiga Cortina de Ferro é um dos motivos de sua decepção com o Ocidente. O momento de medir seu lugar e papel nos dois lados da Europa parece ser, aqui, crucial. Desta operação de medição, o mais antigo seria o vitorioso. A descrição de Linnaeus: levis, argutus, inventor versátil, sagaz, inventivo - em relação ao homo europaeus, a mais alta forma de homo sapiens, cabe melhor aos intelectuais europeus do Leste. Em 1989 retorna à Europa o herói que desapareceu como espécie no século XX e que era para nunca mais voltar. Entre o papel social desempenhado e o reconhecimento social atribuído ao intelectual nos dois lados da Europa, surge uma assimetria. O contraste em questão aparece melhor na seguinte sentença: "A luta pelos direitos humanos deve ser uma preocupação dos intelectuais; o ajuste do imposto sobre o valor agregado não é da conta deles" (LEPENIES, 1991, pp. 911, 914).

Lepenies, em seus estudos, fez referência a eventos extremamente importantes cujo status, no entanto, pode se tornar meramente efêmero. Não importa o que aconteça - do que o autor de Aufstieg und Fall der Intellektuellen in Europa ${ }^{28}$ está perfeitamente consciente e do que ele escreve - o final do século XX testemunhou um retorno heroico do herói que, como uma parte da sociedade mais do que uma figura solitária, nasceu há cem anos na França e rotulouse l'intellectuel ${ }^{29}$. Lepenies diz que "no final do século estamos percebendo, com a queda dos regimes comunistas na Europa Oriental, uma reabilitação do intelectual. Estamos assistindo seu retorno heroico ao palco político" (p. 917). E é precisamente nesta situação, sob tais circunstâncias, que os intelectuais, forçados pelos desenvolvimentos históricos, têm o direito de quebrar a regra dada por Kant e retirada de Bacon: de nobis ipsis silemus, vamos manter silêncio sobre nós mesmos. O ano de 1989 mais uma vez deu um impulso para retornar à reflexão sobre o papel público e político do intelectual. Pois eles tiveram um papel importante nos eventos daquele ano.

Os eventos de 1989 (como também os acontecimentos anteriores e posteriores) parecem não ter encontrado uma elaboração conceitual e não ter levado a repercussões teóricas no discurso dedicado ao intelectual. Talvez a maior influência que estes eventos tenham exercido possam ser encontradas em dois filósofos-sociólogos: Zygmunt Bauman e Wolf Lepenies, ambos por razões diferentes diretamente ligadas à Europa Central. A referência aos eventos de 1989 e o "retorno do herói" são invisíveis no Ocidente, não importa se se lê volumes coletivos publicados no mundo de língua inglesa, como: Intelectuais: Estética, Política, Acadêmicos; Conhecimento e Poder. Os Intelectuais Europeus e a Vida Pública; ou as discussões francesas sobre intelectuais contempladas em livros escritos por Bernard-Henri Lévy, Pascal Ory ou Jean-François Sirinelli (ORY, 1990; SIRINELLI, 1990). Lévy, por exemplo, observa apenas o seguinte: "Na praça Tienanmen, em Praga, e no Muro de Berlim, procuramos sinais de uma época prestes a terminar, uma época em que os intelectuais talvez tenham desfrutado sua maior influência" (LÉVY, 1995, p. 7). E foi exatamente ali que a "assimetria" que Lepenies tem em mente começou a ficar visível. $\mathrm{O}$ tema em questão nunca foi elaborado por tais pensadores.

\footnotetext{
${ }^{28}$ Ascensão e Declínio dos Intelectuais na Europa (N.T.)

${ }^{29} \mathrm{o}$ intelectual (N.T.)
} 
Quais são os tipos específicos de intelectuais que Lepenies consegue ver na Europa Central? Primeiro os "melancólicos ativos" e, depois, "os intelectuais malsucedidos"30 (LEPENIES, 1992, p. 26; 1995, p. 14). Ambos podem ser encontrados apenas nesta parte do mundo. Os "melancólicos ativos" são os intelectuais que, depois de 1989, tomaram o poder nos países pós-comunistas (a um grau e período de tempo variados, não nos esqueçamos); eles são os tais "moralistas" já citados neste texto, os quais, sendo atores, dramaturgos, filósofos, poetas, diretores de filme, artistas, músicos, "preservavam uma certa credibilidade moral, dignidade e habilidade para inspirar os jovens" (LEPENIES, 1991, p. 915), e participaram em movimentos de oposição e depois em revoluções bem-sucedidas. Na mudança de mentalidade que a Europa espera, os "intelectuais malsucedidos", uma espécie extinta no Ocidente por um longo tempo, podem desempenhar um papel crucial na ciência (assim como, na visão de Lepenies, os "rebeldes competentes" podem desempenhar tal papel na economia e os "patriotas cosmopolitas", na democracia). A questão chave para a "lacuna mental" existente entre o Oriente e o Ocidente, em relação aos três domínios mais importantes: ciência (cultura), economia, democracia (LEPENIES, 1995, p. 2), mostra o lugar da cultura como o mais significativo na transformação em andamento. Enquanto, de acordo com Lepenies, na economia e na política o Oriente simplesmente se une ao Ocidente (ou seja, o mercado livre substitui o planejamento central e a democracia parlamentar substitui a ditadura de partido único), na esfera da cultura, o Oriente pode encontrar o Ocidente. Vamos ouvir cuidadosamente a seguinte citação: "Quero argumentar que [este sistema cultural de nossas sociedades - MK] é uma área onde nós do Ocidente deveríamos considerar os recentes desenvolvimentos históricos no nosso continente como a oportunidade mais bem-vinda para aprender com os outros ao invés de simplesmente usar isto como pretexto para ensinar os outros" (1994a, p. 3).

Esta possibilidade de aprender uns com os outros (LEPENIES, 2001) - no domínio da cultura, sem nenhuma tentativa de procurar por uma "terceira via" na economia ou na política - permitiria conservar a diversidade das orientações culturais as quais tradicionalmente têm formado a riqueza da Europa. As conclusões de Lepenies são de grande alcance. Se 1989 "também aconteceu para o Ocidente", para nos lembrar desta convicção fundamental, então o Ocidente deveria tentar fazer uso das lições dadas pela história. A cultura dos especialistas mostrou suas limitações, pois ninguém esperava tal possibilidade: "a derrota do comunismo é, portanto, um motivo muito mais para a modéstia do que para o triunfo - pra todos nós" (LEPENIES, 1995, p. 4). O erro da cultura política Ocidental dos especialistas consiste, na visão de Lepenies, em acalentar a ilusão de uma vitória final, esquecendo o fracasso das convicções utópicas desta cultura que acompanhou o fim da utopia socialista. Pois o capitalismo é uma utopia de meios, não sendo uma utopia de fins utópicos. Esta questão foi colocada de forma explícita em uma palestra em Paris quando ele disse que "o capitalismo, desde suas origens, tem sido apoiado pela convicção de que o progresso da ciência e da tecnologia consiste num meio infalível para transformar o mundo todo em uma vasta sociedade civil universal. Esta ilusão precisa ser renunciada hoje" (LEPENIES, 1992, p. 27). O fim da utopia dos fins influenciou o fim da crença num irresistível progresso da ciência e da tecnologia. Não se leva em consideração que a conexão entre as duas utopias é tanto perigosa quanto míope.

É somente desta perspectiva que o tema seguinte pode ser considerado: A crença de Lepenies na necessidade de conectar a Europa do pensamento com a Europa da política e das elites culturais. Se a cultura e o mundo do pensamento estão passando de mão em mão com as atuais transformações no Oriente e no Ocidente, então a figura crucial é o intelectual citado o tempo todo no presente texto. Portanto, estudando as "vantagens relativas do retrocesso"

\footnotetext{
${ }^{30}$ No original, "non-profit intellectuals" (N.T.)
} 
(LEPENIES, 1995, p. 13) no Leste, Lepenies conclui que as experiências que a figura do "intelectual malsucedido" traz podem ajudar em uma autoanálise dos intelectuais ocidentais hoje. Para apresentar a ideia em poucas palavras, vamos citar duas frases de dois textos: "deveríamos usar o exemplo dele como uma oportunidade para mudar algumas de nossas próprias atitudes intelectuais" e "ele fará algo que precisamos desesperadamente: ensinar-nos as diferenças" (LEPENIES, 1994a, p. 13; 1995a, p. 9). Quando uma cultura restrita dos especialistas fracassa, então é necessário retornar - de uma forma crítica - à tradição do Iluminismo e seu "philosophe"31. Parece que mais uma vez o caráter dos intelectuais iluministas renasceu com a ajuda dos intelectuais da Europa Central, enquanto a história dos intelectuais modernos é a história de sua própria superestimação - o "philosophe"32 de Diderot retornou à cena europeia, com a propriedade, a coragem pessoal, o compromisso com a sociedade civil e a inabalável crença nas possibilidades da razão em tornar o mundo social melhor, com as características que estão sendo apresentadas precisamente pelos "intelectuais que chegaram ao poder nas sociedades pós-comunistas da Europa Oriental" (LEPENIES, 1994, p. 112).

O ethos perdido da coragem pessoal e da modéstia intelectual (mais do que a auto complacência) foi o que se encontrou em 1989, de acordo com Lepenies. E se ele escreve sobre as vantagens relativas do retrocesso e sobre o aprendizado com os outros, então ele certamente quer dizer que os potenciais ganhos culturais podem ser fornecidos pelo choque de cultura dos especialistas céticos e dos moralistas sentimentais. Se a cultura precisa desempenhar suas tarefas fundamentais - e talvez a mais importante seja a mudança de mentalidades - então o intelectual do Iluminismo tem de vir ao palco mais uma vez do mesmo modo que fez na Europa Oriental. Os sonhos de Lepenies de renovação espiritual do Ocidente Europeu, devido aos acontecimentos de 1989, tornaram-se realidade? Não, pois na sua opinião o Ocidente não pensou na sua vitória, não parou por um momento para refletir sobre si mesmo: "nós não estávamos dispostos a assumir as consequências de 1989 em relação à mudança de nossas mentalidades. Como tudo estava mudando no Oriente, estávamos convencidos de que tudo poderia permanecer como sempre foi no Ocidente" (LEPENIES, 1995b, p. 8).

\section{4.}

Portanto, a tarefa principal do intelectual poderia ser descrita da seguinte maneira: apesar do tempo da utopia ter acabado (observe o título do tema la fin de l'utopie ${ }^{33}$ em uma palestra no Collège de France), o intelectual não tem o direito de se abrigar na melancolia novamente (o título do tema le retour de la mélancolie $e^{34}$ ). $\mathrm{O}$ melhor exemplo pode ser tirado dos "melancólicos ativos" da Europa Central e Oriental que ajudam na reabilitação da figura do intelectual e faz lembrar o ethos do Iluminismo. Denis Diderot pode se tornar uma figura do pai fundador em um retorno ao Iluminismo no pensamento sobre o intelectual: ele não só alertou contra uma superestimação do papel da razão, mas também de seu próprio papel. Como Lepenies o descreve, "seu intelectual não vive em uma torre de marfim e sua vida cotidiana não é de exílio. Porque ele sabe que a humanidade só consegue viver em sociedade, ele almeja desenvolver plenamente sua própria sociabilidade, tornar-se útil e agradável aos seus vizinhos. A sociedade civil é tão louvável para ele quanto uma divindade terrena: ele conhece seus princípios mais do que qualquer outra pessoa e vê em sua perfeição o seu maior objetivo" (LEPENIES, 1994, p. 112). A questão sobre o conjunto melancolia-utopia-

\footnotetext{
31 "filósofo" (N.T.)

32 "filósofo" (N.T.)

${ }^{33}$ o fim da utopia (N.T)

${ }^{34}$ o retorno da melancolia (N.T.)
} 
intelectual encontra aqui sua resposta para os dias de hoje: em um mundo sem utopia, o intelectual não pode cair novamente na melancolia, devendo retornar à tradição do Iluminismo (não eurocêntrico) em sua busca por um ideal de compromisso social. Pela primeira vez no século XX, devemos acrescentar, o intelectual tem uma chance de ir além do círculo encantado da melancolia/utopia. Pela primeira vez ele não é seduzido pela "ideologia da ação" - que se mostrava tão desastrosa para várias gerações de escritores, filósofos e artistas engajados em uma mudança revolucionária no curso do mundo.

Lepenies tenta reconduzir o intelectual à tradição da não superestimação de suas próprias possibilidades - seu papel, status e lugar na sociedade - mas, ao mesmo tempo, introduz a cultura em um lugar crucial nas transformações que ocorrem no mundo. As mudanças mínimas têm sugerido que a economia e a política não são suficientes diante do desafio de confrontar o mundo livre da utopia: cultura, ciência e artes retornam a um lugar essencial na vida social. A questão é se Lepenies não faz dos "melancólicos ativos" heróis em excesso - os intelectuais do Leste celebram excessivamente a "cultura política dos moralistas" e admiram excessivamente os "intelectuais malsucedidos" como figuras potencialmente criadoras de exemplos? Obviamente, suas discussões têm, de fato, restrições e quantificadores necessários, mas, ao que parece, ele precisa das figuras pintadas da maneira como ele as pinta para contrastar com a situação do intelectual no Ocidente. Quanto mais colorido é o póscomunismo da Europa Central, mais poderoso é o contraste no qual ele quer focar sua atenção. Se ele está voltado ao mundo Ocidental, então o contraste em questão tem um papel, digamos, pedagógico. Pode-se dizer que ambos elementos da oposição são "tipos ideais", nunca encontrados na realidade a longo prazo. Mas embora a realidade nos conduza a uma resposta de que há cada vez menos "intelectuais sem fins lucrativos" no mundo de acelerada comercialização da cultura e das artes, que os moralistas que lideraram as revoluções e encabeçaram os movimentos de oposição foram, há muito tempo, privados de poder nas eleições democráticas em favor dos especialistas frios (que muitas vezes estão longe do que Lepenies se referiu no Collège de France como probité morale et engagement courageux en faveur des droits de l'homme ${ }^{35}$, para dizer o mínimo) e que o "novo entusiasmo emocional" dos debates e discussões dos anos seguintes a 1989 desapareceu há muito - apenas para se ater aos motivos poloneses - no entanto, o tipo humano mostrado por Lepenies é extremamente estimulante. Este caso e as pessoas ao seu redor foram realmente assim? Como o Leste tem mudado até hoje e qual será a direção destas mudanças a longo prazo? E quanto à ideia de que nós, aqui [no Leste Europeu], levamos em conta a economia e a democracia - e aprendemos as diferenças de cada uma? Estamos nos tornando um "Ocidente mais pobre", desesperadamente tentando compensar as décadas perdidas (KWIEK, 2003)? Lepenies é um dos poucos pensadores no Ocidente que vê estas questões com clareza e tenta expô-las, inspirando ambos os lados em questão. No fervor das controvérsias ideológicas sobre o "fim da história", os debates filosóficos sobre a "morte do intelectual" e as discussões sociológicas sobre o "colapso do comunismo", o discurso de Lepenies sobre o intelectual, a partir da perspectiva da melancolia e utopia, e sua tentativa de nos levar de volta à tradição dos filósofos do Iluminismo, soa realmente muito interessante.

\section{Bibliografia}

BOYER, Par Alain. et al. Pourquoi nous ne sommes pas nietzschéens. Paris: Grasset, 1991.

JENNINGS, Jeremy (ed.). Intellectuals in Twentieth-Century France. Mandarins and Samurais, New York: St. Martin's Press, 1993.

\footnotetext{
${ }^{35}$ integridade moral e compromisso corajoso a favor dos direitos humanos (N.T.)
} 
JENNINGS, Jeremy, KEMP-WELCH, Anthony. Intellectuals in Politics. From the Dreyfus Affair to Salman Rushdi. London and New York: Routledge, 1997.

JUDT, Tony. Past Imperfect. French Intellectuals, 1944-1956. Berkeley: University of California Press, 1992.

KWIEK, Marek (ed.). The University, Globalization, Central Europe. Frankfurt: Peter Lang, 2003.

Agents, Spectators and Social Hope. Theoria. A Journal of Social and Political Theory, New York: Berghahn Books, vol. 101, 2003a.

The Nation-State, Globalization, and the Modern Institution of the University. Theoria. A Journal of Social and Political Theory, New York: Berghahn Books, vol. 96, 2000.

The Dilemmas of Identity. On the Self-Image of the Philosopher in Post-War French Thought. Poznan. Adam Mickiewicz University Press (in Polish), 1999.

After Philosophy: the Novelist as Cultural Hero of Modernity? On Richard Rorty's New Pragmatism. Theoria. A Journal of Social and Political Theory. Oxford and New York: Berghahn Books. Vol. 92, 1998.

Zygmunt Bauman and the Question of the Intellectual. Working Papers, vol. 17, the Center for Western European Studies at the University of California at Berkeley, 1997.

LAWRENCE, P.K. (ed.). Knowledge and Power. The Changing Role of European Intellectuals, Aldershot: Avebury, 1996.

LEPENIES, Wolf. Cultures of Knowledge. Nature. 05 April. 410, 2001.

Alexander von Humboldt - His Past and His Present. BerliNews. 31 Mai, 1999.

Science and Scholarship after the End of History. Bonn, 1995.

Universal Problems and Particular mentalities in our Future Society. Sienne, 1995a.

From the History of Mentalities to a Politics of Mentalities. In Budapest Review of Books, vol. 5, no. 1, Spring, 1995 b.

The Future of Intellectuals, Partisan Review, Winter 1994, vol. 61, no. 1, 1994.

Intellectual responsibilities. Institution Building in Central and Eastern Europe: Some Consequences for the West", Pisa, 1994a.

La fin de l'utopie et le retour de la mélancolie. Regards sur les intellectuels d'un vieux continent, Paris: Collège de France, 1992.

Aufstieg und Fall der Intellektuellen in Europa, Frankfurt. Campus Verlag, 1992a.

Melancholy and Society. Trad. J. Gaines and D. Jones, Cambridge, MA: Harvard University Press, $1992 b$. 
The Failure of the Interpreting Class or Intellectuals in the Two Germanies, in: New Literary History, vol. 22. no. 4, Autumn, 1991.

Between Literature and Science: The Rise of Sociology. Trad. R.J. Hollingdale, Cambridge: Cambridge University Press, 1988.

LÉVY, Bernard-Henri. Adventures on the Freedom Road. The French Intellectuals in the 20th Century. Trad. R. Veasey, London: The Harvill Press, 1995.

ORY, Pascal (ed.). Dernières questions aux intellectuels. Paris: Olivier Orban, 1990.

ORY, Pascal ; SIRINELLI, Jean-François. Les Intellectuels en France, de l'Affaire Dreyfus à nos jours. Paris: Armand Colin, 1986.

SIRINELLI, Jean-François. Intellectuels et passions françaises. Manifestes et pétitions au XXe siècle, Paris: Fayard, 1990.

READER, Keith A. Intellectuals and the Left in France since 1968, London: MacMillan, 1987.

ROBBINS, Bruce. (ed.). Intellectuals: Aesthetics, Politics, Academics. Minneapolis: University of Minnesota Press, 1990.

RORTY, Richard. Achieving Our Country. Leftist Thought in Twentieth-Century America. Cambridge, MA: Harvard University Press, 1998.

STOEKL, Allan. Agonies of the Intellectual. Lincoln: University of Nebraska Press, 1992. 